\title{
A Review of the Significance of Block Chain Technology in Tanzania
}

\author{
Jesca Mhoja Nkwabi \\ University of the West of Scotland \\ Import Building, 2 Clove Cres, London E14 2be, United Kingdom \\ Email:jesyoncy77@gmail.com
}

\begin{abstract}
A block chain refers to a distributed ledger that contains digital information that has been shared among various parties. It is different from other online platforms as it is more secure and difficult to duplicate. Thus, transactions that are shared on the blockchain platform cannot be compromised in any way.Block chain technology has gained significant recognition recently due to the merits that it offers to various businesses. Some of these benefits include reduced paperwork, more transparency, and security.Although, several African countries such as Ghana, Kenya, and Ethiopia have adopted block chain technology to enhance their businesses, the implementation of this technology in Tanzania is still lagging. To address this gap, this paper highlights the benefits of block chain technology and underlines the significance of adopting such a technology in various sectors in Tanzania. For instance, it has been noted that in the Tanzanian healthcare system patient records are being maintained manually, which makes it difficult for doctors to access the medical history of patients. Furthermore, there is also a tendency for medical reports to be stolen and tampered with. In contrast, it has been identified that land registration in Tanzania is weak and is mainly affected by bureaucracy, corruption, and lack of transparency. Furthermore, having such a weak land registration system has resulted in many impediments to society, such as conflicts which have resulted in the loss of life and property. In the Tanzanian banking sector, it has been identified that network failure, poor security, theft of funds are still issues that interfere with the effective performance of banks. In light of these drawbacks, the implementation of block chain technology can offer improved systems in Tanzania such as enhanced security in managing patient records, transparency in land registration systems and minimization of fraud in banks. Thus, in recognising the significance of blockchain technology in Tanzania, it is imperative for the government as well as various businesses sectors to invest in blockchains in order to derive the benefits.
\end{abstract}

Keywords: Block chain technology, Tanzania, Transparency, Increased Security, Digital Tracking

DOI: $10.7176 / \mathrm{EJBM} / 13-16-01$

Publication date:August $31^{\text {st }} 2021$

\section{Introduction}

A block chain is a distributed ledger containing transactions or digital information that has been shared among the participating parties (Kouhizadeh, Saberi \& Sarkis, 2021). Each transaction shared within the block chain is verified by a majority of members. Over the years blockchain technology has gained much attention mainly because, unlike other platforms, block chain users can verify each and every transaction without compromising the privacy of users (Crosby et al., 2016). Reduced paperwork, transparency, and security are some of the benefits that are offered by block chains. For instance, previously it was hard to manage paperwork between members of the supply chain when shipping goods from Europe to African nations. With the use of blockchains, members can interact digitally, track shipments, and ensure that goods reach the port on time. Also, it has previously been difficult to track ingredients from suppliers, but with blockchain technologies manufacturers can trace defective ingredients from suppliers in just two weeks. Another vivid example is the prevention of counterfeit products. Block chain delivers transparency to consumers. Customers can now track whether the seller is the genuine owner of the product, this is most prevalent in the mining sector where some buyers are at the risk of dealing with minerals from the black market (Hussien et al., 2021). Notwithstanding the benefits that block chain has to offer to developing nations, Tanzania in particular still lags behind in its implementation. This paper will therefore document the benefits of block chain technology and highlight its importance to various sectors in Tanzania.

\section{LITERATURE REVIEW}

\subsection{Meaning of block chain}

A block chain is a distributed ledger of transactions that has been shared among the participating members (Saberi et al., 2018). Block chain is different from existing technologies as it provides members with more security, transparency, decentralisation, and the ability to create smart contracts (Crosby et al., 2016). Furthermore (Saberi et al., 2018) promulgate that information that is shared on block chains is difficult to amend or hack making it a more secure platform to exchange information. 
There are four different types of block chains that enterprises can use. These include public, private, consortium and hybrid block chains. Public blockchains can be accessed by any member of the public. Conversely, private block chains are only accessible by a small group of people usually a small firm. On the other hand, consortium blockchains are usually used by multiple organisations to authenticate transactions (Schlecht, Schneider \& Buchwald, 2021).In contrast hybrid transaction combines both the private and public block chains to offer flexibility to members (Parizo, 2021).Various firms must choose blockchains that are suitable for their organisations. For example, public block chains are mainly used in mining bitcoins whereas consortium block chains are popular among banks.

\subsection{Significance of block chains}

Block chain technology offers ample merits to various businesses. Numerous researchers have documented these benefits. This is demonstrated in Table 1.

Table 1 Significance of Block Chains

\begin{tabular}{|c|c|}
\hline Researcher & Benefits of Block chain technologies \\
\hline Abeyratne (2016) & $\begin{array}{l}\text { - Exchange of digital currencies i.e., bitcoin. } \\
\text { - Decentralized stock markets. } \\
\text { - } \text { Digital identity. } \\
\text { - } \text { Asmart contracts. } \\
\text { - Engineering applications, controlling quality tests, product tracking } \\
\text { and distribution of modular designs for machines. }\end{array}$ \\
\hline Saberi et al., (2018) & $\begin{array}{l}\text { - } \quad \text { Reliability and transparency in the supply chain. } \\
\text { - } \quad \text { Traceability in the supply chain. } \\
\text { - } \quad \text { Detect defective goods. } \\
\text { - } \quad \text { Reduce costs. } \\
\text { - } \quad \text { Smooth distribution of products. }\end{array}$ \\
\hline Francisco \& Swanson, (2018) & - $\quad$ Supply chain transparency. \\
\hline Clauson et al., (2018) & - Detecting counterfeit medicines in the market. \\
\hline Min, (2019) & $\begin{array}{l}\text { - Offers supply chain resilience through mitigating risks that are } \\
\text { associated with intermediaries interventions, including issues such as } \\
\text { hacking, compromised privacy, political turmoil, bureaucracy } \\
\text { instability of financial institutions, and contractual disputes. }\end{array}$ \\
\hline Zhang \& Kamel (2020) & $\begin{array}{l}\text { - } \quad \text { Managing medical devices. } \\
\text { - } \quad \text { Securing patient identities. } \\
\text { - } \quad \text { Medical fraud detection. } \\
\text { - }\end{array}$ \\
\hline Mackey et al., (2020) & $\begin{array}{l}\text { - } \quad \text { Reducing national public health expenditures. } \\
\text { - } \quad \text { Meeting higher demand for healthcare services. }\end{array}$ \\
\hline $\begin{array}{l}\text { Katsikouli, Wilde, Dragoni \& } \\
\text { Høgh - Jensen, (2020) }\end{array}$ & $\begin{array}{l}\text { - } \quad \text { Minimising data duplication. } \\
\text { - } \quad \text { Minimum transaction duration. } \\
\text { - } \quad \text { Reduced paperwork distortion. }\end{array}$ \\
\hline Pandey \& Litoriya, (2020) & $\begin{array}{l}\text { - } \quad \text { Secure and transparent system of integrated healthcare services. } \\
\text { - } \quad \text { Eliminating corruption in national health-insurance programmes. }\end{array}$ \\
\hline
\end{tabular}

As portrayed in Table 1 above there are numerous merits of implementing block chain technology. For example, Saberi et al. (2018) point out that block chain technology has several benefits in the supply chain. For instance, in the food supply chain, block chain facilitates participating partners with real time food tracing following HACCP (Hazard Analysis and Critical Control Points) rules. Furthermore, Staples et al. (2017) suggest that block chain technology can record supply chain incidents in the agricultural sector. Also, through block chain technology, unethical suppliers of defective goods can be identified since only authorised actors can record information. Additionally, block chain technology can help to reduce costs in the supply chain since there are no transaction costs incurred while interacting with members, which saves time as interactions take place online. Other advantages of block chain technology in the supply chain include instant sharing of any modified data, which allows the smooth distribution of products, supply chain transparency, and supply chain resilience (Katsikouli, Wilde, Dragoni \& Høgh - Jensen, 2020).

Apart from offering benefits in supply chains Abeyratne (2016) suggested other benefits of blockchain technology in various areas (financial, social, legal, and engineering). The financial benefits of blockchain include exchange of digital currencies such as bitcoin and being able to trade stocks digitally without control 
from stock bodies, thus allowing transparency and fairness in trading. In social applications block chain users gain unique digitalised identities which offer more security. For example, block chain can provide voters with unique voting IDs which can be used to authenticate voting processes. Conversely, in the law field block chain technology offers speedy contracts which eliminate human involvement. With smart contracts users can create, execute, and enforce contracts through block chains at a lower cost. In engineering processes block chain technology can help users to control financial transactions between firms, track products before and after manufacturing, and control quality.

Clauson et al., (2018) noted that in the pharmaceutical industry block chain has helped to track down counterfeit medicines which are harmful to consumers. Others, (Zhang \&Kamel,2020; Mackey et al., 2020) have stated that managing medical devices, securing patient identities, medical fraud detection, public health surveillance, reducing national public health expenditures, meeting higher demand for health care services, secure and transparent system of integrated healthcare services, and eliminating corruption in national healthinsurance programs are key advantages of block chain technology in the medicine industry.

On the other hand, block chain implementation has several challenges, as highlighted in section 2.3.

\subsection{Challenges of block chain implementation}

In spite of the numerous benefits of block chain technology, there are still challenges that affect the implementation of block chain technology. In their study, Batubara et al. (2018) found technological issues (scalability, cybersecurity issues, trust issues), organisational issues (organisational readiness and acceptance, complex structures) and environmental issues (laws and regulations, support infrastructure) to be the main challenges affecting block chain implementation. Zheng et al. (2017) reported technical issues to be the main impediment affecting the effective adoption of block chains. In their study Zheng et al., (2017) argue that blockchain applications such as bitcoin are limited to only $1 \mathrm{MB}$ and are restricted to 7 transactions per second, making it unsuitable to deal with high frequency trading.

Other academics, (Kumar et al., 2019; Pillai et al., 2020) stress that high costs, privacy issues, integration, and usability to be the major concerns in adopting block chains. They further suggest that for block chains to be well implemented in firms it is vital to understand whether parties require public or private block chains and the usability and scalability of the platforms. Also, an understanding of the computed mechanisms is essential to avoid integration issues. Having detailed the challenges of block chain technology, section 2.4 will highlight why block chain technology is vital in Tanzania.

\subsection{Block chain significance in Tanzania}

Tanzania is located in East Africa and has a population of over 55 million people ("Tanzania Overview", 2020). The majority of businesses (95\%) in Tanzania are small and medium enterprises (SMEs) that are engaged in various businesses such as manufacturing, retail and trade, agricultural, and services (Nkwabi \& Mboya, 2019). Tanzania as a country still faces challenges in various sectors such as manufacturing, retail, services, healthcare, and the infrastructure sector. Some of these challenges include data management problems, particularly for voting, natural resources, land administration, authenticity certificates, e-commerce, media, and agriculture (Canellis, 2018).

Although several countries in Africa, such as Ghana, Ethiopia and Kenya have adopted block chain technology and reaped its benefits, block chain technology is still at its infancy stage in Tanzania. For example, in Kenya block chain technology has assisted micro lending to farmers. In Ghana, block chain technology has helped over $80 \%$ of landowners to register and claim their lands. Meanwhile in Ethiopia blockchain technology is applied to track coffee exports and authenticate the origin of coffee and its exposure to chemicals (Kombe et al., 2019).

In Tanzania, however, the implementation of block chain technology still lags behind. In a study by Kombe et al. (2019), it was revealed that if implemented in the healthcare sector, block chain can facilitate security. Currently, the majority of the hospitals in Tanzania suffer from security issues, mainly in maintaining patient records. As noted by Kombe et al. (2019), even unauthorised users can access patient information, as a result patient confidentiality and privacy is compromised which can lead to serious issues such as identity theft and manipulation.

Furthermore, the study also observed that sharing of information between hospitals is difficult as hospitals do not have the means to transfer patient records, which leads to patients having to undergo the same medical tests which were carried out in another hospital. Such an act is expensive and time consuming to both the patient and the hospital. Other challenges that were revealed from the study include low bandwidth usage and inaccurate data.

Another study by Kombe et al. (2017) revealed that block chain technology can assist land registration and information systems in Tanzania. Presently, the land registration procedure in Tanzania is weak. Bureaucracy, corruption, and lack of transparency are some of the challenges that affect the various sectors in Tanzania 
(Kombe et al., 2017). These obstacles have resulted in loss of lives, properties, homes, and conflicts in Tanzanian society. Although the government has introduced an Integrated Land Management Information System (ILMIS), security and storage of data is still a major concern in the land registration sector. Furthermore, the process remains time consuming as it takes about 40 days for registration to be complete. With the presence of block chain technology, however, land registration procedure duration can be reduced. Furthermore, data registered can be protected from unauthorised changes. Also, participating parties can achieve transparency as only one plot owner can be recognised and authenticated in the system (Kombe et al., 2017).

In the banking sector several researchers in Tanzania have revealed challenges affecting the banking sector. Mashenene \& Mkende (2019) found that network failure, theft of transferred funds, delay of fund delivery, and reconciliation to be major challenges impacting mobile banking usage in Tanzania. Jelodar (2016) reported issues such as fraud and poor internal control to be factors impacting the banking sector. In the education sector, Tanzanian institutions are yet to implement sophisticated systems to store student records, as a result there have been several instances of degree fraud. With the help of block chain technology, security, transparency, and reliable storage of vital data can be achieved in Tanzania.

\section{Discussion and Conclusion}

From the evidence from previous studies discussed in the above sections. Tanzania can indeed benefit greatly from the implementation of block chain technology. Since blockchain technology offers security, anonymity, confidentiality, and transparency. Problems that are affecting the various Tanzanian sectors which include healthcare, land registration, banks, and the education sector can be easily resolved. From previous studies (Jelodar, 2016; Kombe et al., 2017; Kombe et al., 2019) it is noted that data management and storage is the predominant issue affecting these sectors. With the presence of block chains, Tanzanian sectors stand a chance of securing their data and preventing fraud. Furthermore, costs that are incurred in traditional methods such as land registry and recording patient information can indeed be resolved.

This study has implications for practitioners, policymakers, and researchers. For practitioners this article shows the benefits that Tanzania can achieve through implementation of blockchain. This study has also provided examples of other African countries like Kenya and Ghana who have started implementing blockchain technology. For policymakers, efforts should be made to facilitate businesses in Tanzania to implement block chain technology. For researchers, this paper has only provided an overview of the significance of block chain technology in Tanzania. Since studies on blockchain technology are scarce, it would therefore be useful to see more studies on how Tanzanian businesses can benefit from blockchain technology. Also, due to the fact that block chain technology is still a new concept in Tanzania, it would be essential to see studies addressing how successful implementation of block chain technology can happen in different sectors such as healthcare, business, education, law etc. Researchers can also conduct surveys, in both developed and developing nations, and highlight the significance and challenges of block chain implementation and suggest ways on how successful block chain technology implementation can take place.

\section{References}

Abeyratne, S. (2016). Blockchain Ready Manufacturing Supply Chain Using Distributed Ledger. International Journal Of Research In Engineering And Technology, 05 (09), 1-10.

Andoni, M., Robu, V., Flynn, D., Abram, S., Geach, D., \& Jenkins, D. et al. (2019). Blockchain technology in the energy sector: A systematic review of challenges and opportunities. Renewable And Sustainable Energy Reviews, 100, 143-174.

Batubara, F., Ubacht, J., \& Janssen, M. (2018). Challenges of blockchain technology adoption for egovernment. Proceedings Of The 19Th Annual International Conference On Digital Government Research Governance In The Data Age - Dgo '18.

Canellis, D. (2018). Tanzania: Government to research blockchain tech, but very slowly. Hard Fork | The NextWeb.Retrieved26March2020,fromhttps://thenextweb.com/hardfork/2018/10/29/tanzania-blockchainresearch.

Clauson, K., Breeden, E., Davidson, C., \& Mackey, T. (2018). Leveraging Blockchain Technology to Enhance Supply Chain Management in Healthcare: Blockchain In Healthcare Today,1,1-12.

Crosby, M., Nachiappan, Pattanayak, P., Verma, S., \& Kalyanaraman, V. (2016). BlockChain Technology: Beyond Bitcoin. Applied Innovation Review, (2),7-19.

Fallah Jelodar, M. (2016). Prioritization of the Factors Affecting Bank Efficiency Using Combined Data Envelopment Analysis and Analytical Hierarchy Process Methods. Journal Of Optimization, 2016, 1-7.

Francisco, K., \& Swanson, D. (2018). The Supply Chain Has No Clothes: Technology Adoption of Blockchain for Supply Chain Transparency. Logistics, 2 (1), 2.

Hussien, H., Yasin, S., Udzir, N., Ninggal, M. \& Salman, S., 2021. Blockchain technology in the healthcare industry: Trends and opportunities. Journal of Industrial Information Integration, [online] 22,100217. 
Katsikouli, P., Wilde, A., Dragoni, N. \& Høgh - Jensen, H., 2020. On the benefits and challenges of blockchains for managing food supply chains. Journal of the Science of Food and Agriculture, 101(6), 2175-2181.

Kombe, C., Sam, A., Ally, M., \& Finne, A. (2019). Blockchain Technology in Sub-Saharan Africa: Where does it fit in Healthcare Systems: A case of Tanzania. Journal Of Health Informatics In Developing Countries, 13(2), 1-19.

Kombe, M., Manyilizu, D., \& Mvuma, P. (2017). Design of Land Administration and Title Registration Model Based on Blockchain Technology. Journal Of Information Engineering And Applications, 7 (1),8-15.

Kouhizadeh, M., Saberi, S. \& Sarkis, J., 2021. Blockchain technology and the sustainable supply chain: Theoretically exploring adoption barriers. International Journal of Production Economics, [online] 231, 107831.

Kumar, A., Liu, R., \& Shan, Z. (2019). Is Blockchain a Silver Bullet for Supply Chain Management? Technical Challenges and Research Opportunities. Decision Sciences, 51(1), 8-37.

Mackey, T., Bekki, H., Matsuzaki, T., \& Mizushima, H. (2020). Examining the Potential of Blockchain Technology to Meet the Needs of 21 st-Century Japanese Health Care: Viewpoint on Use Cases and Policy. Journal Of Medical Internet Research, 22(1), e13649.

Mashenene, R., \& Mkende, E. (2019). Benefits And Challenges Of Mobile Phone Banking Usage In National Microfinance Bank Dodoma, Tanzania. Business Education Journal, 2 (2), 1-10.

Min, H. (2019). Blockchain technology for enhancing supply chain resilience. Business Horizons, 62(1), 35-45.

Nkwabi, J., \& Mboya, L. (2019). A Review of Factors Affecting the Growth of Small and Medium Enterprises (SMEs) in Tanzania. European Journal Of Business And Management,11(33),1-8.

Pandey, P., \& Litoriya, R. (2020). Implementing healthcare services on a large scale: Challenges and remedies based on blockchain technology. Health Policy And Technology, 9 (1), 69-78.

Parizo, C., 2021. What are the 4 different types of blockchain technology? [online] SearchCIO. Available at: $<$ https://searchcio.techtarget.com/feature/What-are-the-4-different-types-of-blockchain-technology> [Accessed 19 August 2021].

Pillai, B., Muthukkumarasamy, V., \& Biswas, K. (2020). Challenges in Designing a Blockchain Platform. $\begin{array}{llllll}\text { Research } & \text { gate. } & \text { Retrieved } & 8 & \text { April } & \text { 2020, from }\end{array}$ https://www.researchgate.net/profile/Kamanashis_Biswas/publication/317617799_Challenges_in_Designin g_a_Blockchain_Platform/links/5943ccad45851525f890a0a9/Challenges-in-Designing-a-BlockchainPlatform.pdf.

Saberi, S., Kouhizadeh, M., Sarkis, J., \& Shen, L. (2018). Blockchain technology and its relationships to sustainable supply chain management. International Journal Of Production Research, 57 (7), 2117-2135.

Schlecht, L., Schneider, S. and Buchwald, A., 2021. The prospective value creation potential of Blockchain in business models: A delphi study. Technological Forecasting and Social Change, 166, 120601.

Tanzania Overview. World Bank. (2020). Retrieved 26 March 2020, from https://www.worldbank.org/en/country/tanzania/overview.

Zhang, P. \& Kamel, M., 2020. Chapter 50 - Blockchain solutions for healthcare. In: J. Faintuch and S. Faintuch, ed., Precision Medicine for Investigators, Practitioners and Providers, 2nd ed. [online] Academic Press, pp.519-524. Available at: <https://doi.org/10.1016/B978-0-12-819178-1.00050-2> [Accessed 24 August 2021].

Zheng, Z., Xie, S., Dai, H., Wang, H., \& Chen, X. (2017). An Overview of Blockchain Technology: Architecture, Consensus, and Future Trends. Research gate. Retrieved 8 April 2020, from https://www.researchgate.net/profile/Hong-

Ning_Dai/publication/318131748_An_Overview_of_Blockchain_Technology_Architecture_Consensus_an d_Future_Trends/links/59d71 faa458515db19c915a1/An-Overview-of-Blockchain-TechnologyArchitecture-Consensus-and-Future-Trends. 